\title{
Peripheral NK and B regulatory cell frequencies are altered with symptomatic exacerbation in generalized myasthenia gravis patients
}

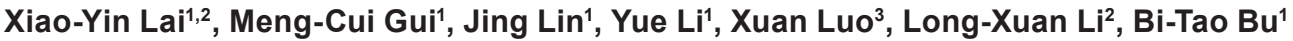 \\ ${ }^{I}$ Department of Neurology, Tongji Hospital, Tongji Medical College, Huazhong University of Science and Technology, Wuhan 430030, Hubei, China. \\ ${ }^{2}$ Department of Neurology, Gongli Hospital, Pudong New Area, Shanghai 200135, China. \\ ${ }^{3}$ Teaching and Research Office of Hygiene, 95890 Unit, Chinese People's Liberation Army, Wuhan 430000, Hubei, China.
}

Correspondence to: Dr. Bi-Tao Bu, Department of Neurology, Tongji Hospital, Tongji Medical College, Huazhong University of Science and Technology, 1095 Jiefang Ave., Wuhan 430030, Hubei, China. E-mail: bubitao@tjh.tjmu.edu.cn; Dr. Long-Xuan Li, Department of Neurology, Gongli Hospital, 219 Miaopu Road, Pudong New Area, Shanghai 200135, China. E-mail: Longxuanlee2006@yahoo.com

How to cite this article: Lai XY, Gui MC, Lin J, Li Y, Luo X, Li LX, Bu BT. Peripheral NK and B regulatory cell frequencies are altered with symptomatic exacerbation in generalized myasthenia gravis patients. Neuroimmunol Neuroinflammation 2017;4:179-87.

Dr. Bi-Tao Bu is a professor of Neurology Department, Tongji Hospital, Huazhong University of Science and
Technology (HUST) in China. He had been educated at Hunan Medical College and Tongji Medical College of
HUST respectively. He also had been trained at University of Washington for 2 years and at University of California
at Davies for 1 year. He has been devoted to the clinical and basic studies on myasthenia gravis, inflammatory
myopathies and neuromyelitis optica spectrum disorder. His study has been sponsored by Natural Science
Foundation of China and Sino-German Joint Education Foundation. He is the member of Chinese Medical Society,
Chinese Immunology Society, and American Society for Neurosciences.
Dr. Long-Xuan Li currently serves as the professor and director in the Department of Neurology in Gongli Hospital,
Shanghai. He is the Doctoral Supervisor of The Second Military Medical University and was awarded with the
100-Talents Program of the Shanghai Municipal Health Bureau in 2017. He graduated with a doctorate degree in
Tongji Medical College of Huazhong University of Science and Technology in 2003, and further got postdoctoral
trainings at VA Medical Center of Kansas City, MO and the Scripps Research Institute, CA during 2006-2010.
He also got clinical training at Cleveland Clinic, OH in 2015, and worked as a Visiting Scholar at Mayo Clinic,
FL in 2017. He has nearly twenty years of experiences in practicing clinical neurology with focus on stroke and
neurodegenerative diseases.

Article history:

Received: 20 Jun 2017

Accepted: 24 Jul 2017

Published: 18 Sep 2017

\section{ABSTRACT}

Aim: Myasthenia gravis (MG) is an autoimmune disease, in which immunotherapy can improve symptoms for a period, but the majority of patients still experience symptomatic fluctuation or develop myasthenic crisis. This study aimed to explore the relationship between frequency of peripheral lymphocyte subsets and myasthenia gravis disease stage. Methods: The percentages of B regulatory (Breg) cells and natural killer (NK) cells in the peripheral 


Key words:
Myasthenia gravis,
lymphocyte subsets,
natural killer cells,
B regulatory cells

\section{INTRODUCTION}

Myasthenia gravis (MG) is one of the most common autoimmune neurological diseases and affects the neuromuscular junction. ${ }^{[1]}$ Although there are many therapeutic methods such as immunosuppressive therapy and steroids which are generally regarded as the effective preventive measures leading to marked symptomatic improvement in the majority of MG patients, there are many cases who still experience fluctuating muscle weakness and fatigability to some degree, or develop myasthenic crisis even after a clinical remission. ${ }^{[2-5]}$ Yet the factors predicting the symptomatic fluctuation have not been well defined.

MG is mainly mediated by acetylcholine receptor antibodies (AChR-Ab), which were demonstrated to be associated with the severity of disease in individuals. ${ }^{[6]}$ However, the heterogeneity of AChR-Ab and no elevated titers of AChR-ab in the minority of MG patients limited the clinical significance of measuring the antibodies..$^{[1,7]}$ In addition, there are some patients with elevated titers of antibodies against musclespecific kinase (MuSK), Titin, RyR and LRP4, ${ }^{[8-11]}$ signifying the heterogeneity of the autoimmune disease. Identification of specific markers of disease activity and severity is of great interest to clinicians. Changes in peripheral lymphocyte subsets were reported in patients with $M G$ as well as patients with other autoimmune diseases, including systemic lupus erythematosus, ${ }^{[12]}$ rheumatoid arthritis ${ }^{[13]}$ and Sjogren's syndrome, ${ }^{[14,15]}$ suggesting that these abnormal distributions of lymphocyte subsets may be involved in the pathogenesis of autoimmune diseases. ${ }^{[16-19]} \mathrm{CD} 4^{+}$ Thelper cells have an important role in an experimental animal model of myasthenia gravis (EAMG) and MG patients as they influence autoreactive $B$ cell production of anti-AChR antibodies. ${ }^{[20]}$ Th1, Th2, Th17 and regulatory $T$ (Treg) cells, which were differentiated from Naïve $\mathrm{CD}^{+} \mathrm{T}$ cells, have been shown to be involved in the pathogenesis of MG. ${ }^{[21]} \mathrm{B}$ cells, because of the key contribution to humoral immune responses involving the secretion of antibodies, are generally considered to be pathogenic in the majority of autoimmune diseases. Recent evidence indicates that specific $B$ cell subsets can negatively regulate immune responses by constraining Th1 and Th17 responses, indicative of the existence of regulatory $B$ (Breg) cells. ${ }^{[22]}$ Natural killer (NK) cells predominantly participate in the innate immune response to infections. NK cell-derived interferon-gamma activates Th1 helper cells, ${ }^{[23]}$ and NK cells can impact acquired immunity. The subsets of lymphocytes mentioned above have been demonstrated to be involved in the pathogenesis of MG, but the role of lymphocyte subsets in symptomatic exacerbation in MG patients is not fully understood.

NK cells which play an important role during viral infection and tumor diseases, were considered to be involved in the regulation of autoimmunity in animal models and in humans. ${ }^{[24-26]} \mathrm{NK}$ cell numbers were found to decline with progression of most autoimmune diseases of humans. ${ }^{[27-29]}$ Interestingly, the number of NK cells was increased significantly after plasmapheresis in patients with MG, indicating that they may become an important marker for monitoring clinical activation in MG patients. ${ }^{[16]}$

Traditionally, B cells have been thought to contribute to the antigen $(\mathrm{Ag})$-specific autoantibody production. Nonetheless, the role of $B$ cells extends beyond the production of antibodies in autoimmune diseases. Recently, B cell subsets with regulatory functions were identified and the studies focused on Breg cells, also known as B10 cells, which express IL-10 and CD1 $d^{+}{ }^{+} D 5^{+}$CD $19^{+}$phenotypes. ${ }^{[30-32]}$ Recent studies showed that Breg cells can prevent the development of EAMG, ${ }^{[33]}$ and were involved in patients with autoimmune diseases. ${ }^{[31,34-36]}$ However, whether there are corresponding changes in Breg cells associated with severity of diseases remains elusive.

In this study, we investigated the changes in peripheral NK cells and Bregs in MG patients experiencing deterioration, in attempt to find a reliable marker 
for MG activity and for monitoring effectiveness of immunotherapy.

\section{METHODS}

\section{Patients}

In this study, 54 patients with MG who met the standard clinical criteria ${ }^{[37]}$ and 10 healthy controls $(\mathrm{HC}), 4$ men and 6 women, aged $38.50 \pm 16.37$. All the participants signed the informed consent prior to the enrollment. The study was performed in accordance with the 1964 Declaration of Helsinki (including amendments) and has been approved by the Ethics Committee of Huazhong University of Science and Technology. Exclusion criteria were severe heart diseases, severe kidney diseases, severe mental illness, acute or chronic hepatitis, tuberculosis or HIV infection. The mean \pm standard deviation of the ages of the patients was $40.30 \pm 14.81$ years. The sex ratio (male:female) was 28:15. The clinical features of the participants were summarized in Table 1. Eleven patients presented with ocular MG (OMG) (age: 35.36 \pm 4.57; sex ratio: $5: 6$ ), and 43 with generalized MG (GMG). The GMG patients were further divided into two groups according to the clinical status. Group I included 25 patients who were in exacerbation stage (PE), presenting symptomatic exacerbation or myasthenic crisis (age: $44.52 \pm 2.58$; sex ratio: 8:17). Group II consisted of 18 patients who were in remission $(P R)$, manifesting slight limb weakness or ocular symptoms for at least three months (age: $35.44 \pm 3.66$; sex ratio: 7:11). Overall, 43 patients were on prednisone and trans-sternal extended thymectomy was performed on 30 patients, including 8 with thymic hyperplasia and 22 with thymoma. The identified factors which provoked the deterioration of
MG symptoms were upper respiratory tract infection (14 cases), inappropriate drug use (4 cases), surgery (1), exhaustion (1), and stress (1) [Table 2].

\section{Flow cytometric analysis}

The peripheral blood samples from all the participants were obtained by venipuncture and stored in tubes containing ethylene diamine tetraacetic acid (5.4 mg/tube). Each sample was divided into 2 tubes, each one containing $100 \mu \mathrm{L}$ fresh whole blood which was further incubated with $5 \mu \mathrm{L}$ of mAbs (Becton Dickinson) for $20 \mathrm{~min}$ in dark at room temperature. Breg cells were stained with FITC conjugated antihuman CD19, PE conjugated anti-human CD1d, APC conjugated anti-human CD5, and NK cells were analyzed after staining with $\mathrm{PE}$ conjugated anti-human CD16, PerCP conjugated anti-human CD3, APC conjugated anti-human CD56, respectively. Isotypematched immunoglobulin served as control for analysis of $\mathrm{CD} 1 \mathrm{~d}^{+} \mathrm{CD} 5^{+} \mathrm{CD} 19^{+} \mathrm{B}$ cells and CD3-CD16 ${ }^{+} \mathrm{CD} 56^{+}$ NK cells. After incubation, erythrocytes were lysed with FACS lysing solution (Becton Dickinson). The remaining cells were resuspended in PBS then at least 30,000 lymphocyte events were acquired from each tube to determine their proportions using the FACS Caliber flow cytometer (Becton Dickinson).

\section{Statistical analysis}

All statistical analyses were performed using the SPSS software application. The data were expressed as the mean \pm standard error. For a comparison of the different subgroups of the MG patients and the healthy controls, the data were analyzed using twotailed Student's $t$-test. $P$-values lower than 0.05 were considered to be statistically significant.

Table 1: Clinical characteristics of the MG patients

\begin{tabular}{|c|c|c|c|}
\hline Characteristic & $\begin{array}{l}\text { Patients in exacerbation } \\
\text { (number) }\end{array}$ & $\begin{array}{c}\text { Patients in remission } \\
\text { (number) }\end{array}$ & $\begin{array}{c}\text { Ocular MG } \\
\text { (number) }\end{array}$ \\
\hline \multicolumn{4}{|l|}{ Gender } \\
\hline Female & 17 & 11 & 6 \\
\hline Male & 8 & 7 & 5 \\
\hline Age (year, mean $\pm S D)$ & $44.52 \pm 2.58$ & $35.44 \pm 3.66$ & $35.36 \pm 4.57$ \\
\hline \multicolumn{4}{|l|}{ Osserman's classification } \\
\hline Class I & & & 11 \\
\hline Class Ila & 1 & 6 & \\
\hline Class IIb & 21 & 12 & \\
\hline Class III & 1 & & \\
\hline Class IV & 2 & & \\
\hline Thymoma & 9 & 11 & 2 \\
\hline With thymectomy & 6 & 8 & 1 \\
\hline Thymic hyperplasia & 1 & 5 & 2 \\
\hline With thymectomy & & 3 & 1 \\
\hline Use of prednisone & 24 & 17 & 2 \\
\hline \multicolumn{4}{|l|}{ Immunosuppressant } \\
\hline Tacrolimus & 1 & & \\
\hline
\end{tabular}

MG: myasthenia gravis; SD: standard deviation 


\section{RESULTS}

\section{Frequencies of Breg cells decreased in the peripheral blood of GMG patients}

We have analyzed the frequencies of peripheral Breg cells in the MG patients. CD19+CD1 $\mathrm{d}^{+} C D 5^{+} \mathrm{B}$ cells are routinely regarded as Bregs. To characterize the Breg cell subpopulation, we have determined their surface expression of CD1d and CD5 with CD19 gating, the 2 markers that are believed to be co-expressed by "regulatory" B cells. ${ }^{[38]}$ The data revealed that the percentage of $C D 1 d^{+} C D 5^{+}$cells among the CD19+ were significantly decreased in both the exacerbation stage $(6.93 \pm 1.18)$ and remission stage $(6.56 \pm 1.32)$ of GMG patients compared to healthy controls ( 15.97 \pm 2.88; $P=0.001$ and $P=0.002$, respectively) and topatients with OMG $(16.08 \pm 2.88 ; P=0.001$ and $P$ $=0.002$, respectively). Bregs in the peripheral blood of OMG patients did not show any decrease, instead a slight increase. But no significant difference was found between those in the ocular MG patients and the controls $(P=0.978)$. The imbalance of Bregs in GMG was more obvious. Usually the patients with GMG display different levels of severity, and a lot of patients may experience symptomatic fluctuation or develop myasthenic crisis. In order to clarify whether Breg cells play a key role during symptomatic exacerbations, we further compared the frequencies of these cells at different stages of GMG patients, and found that the

Table 2: Factors leading to exacerbation

\begin{tabular}{lcc|}
\hline Factor & Number & Ratio (\%) \\
\hline Infection & 14 & 56 \\
Inappropriate drug use & 4 & 16 \\
Unknown cause & 4 & 16 \\
Surgery & 1 & 4 \\
Exhaustion & 1 & 4 \\
Stress & 1 & 4 \\
\hline
\end{tabular}

frequencies of Breg cells in GMG patients were not significantly different between stages $(6.93 \pm 1.18$; $6.56 \pm 1.32 ; P=0.834$ ) [Table 3; Figure 1].

\section{Frequencies of NK cells correlate with clinical} stages of GMG patients

NK cells (CD3-CD19+ ${ }^{+}$CD56 $\left.^{+}\right)$are an important player in the regulation of acquired immunity and the levels in the peripheral blood of MG patients have been analyzed. The percentage of CD3-CD19+CD56 ${ }^{+} \mathrm{NK}$ cells was increased to different degrees, especially in GMG patients in remission stage $(20.69 \pm 3.45)$ compared to healthy controls $(11.33 \pm 0.95 ; P=$ $0.017)$. In the patients with OMG, who presented with mild symptoms, NK cells tended to increase compared with those in the healthy controls $(18.98 \pm 3.81)$. Yet the increase was less than that in GMG patients in remission stage and there was no statistical difference. The percentage of NK cells in the GMG patients at exacerbation stage also tended to increase, but the difference was not significant when compared with that in the healthy controls $(12.32 \pm 1.42)$. In order to determine whether NK cell frequencies were associated with symptomatic exacerbation, the percentages of NK cells were compared between the two subgroups of GMG patients. The frequency of NK cells in the patients in remission were significantly increased compared to patients in exacerbation $(20.69 \pm 3.45$ vs. $12.32 \pm 1.42, P=0.017$, Table 4 , Figure 2). The data suggest that NK cells are involved in the pathogenesis of MG and mayplay a protective role during development of the disease.

Frequency of lymphocyte subsets in patients with exacerbation and infection

It's well known that various factors such as infections, inappropriate drug use, or neuro-endocrine dysfunction

Table 3: Frequencies of Breg cells in the peripheral blood of MG patients (\%)

\begin{tabular}{|c|c|c|c|c|c|}
\hline Group & Number & $\mathrm{CD} 19^{+} \mathrm{CD} 1 \mathrm{~d}^{+} \mathrm{CD}^{+} \mathrm{B}$ cells & $P$ value $^{\text {a }}$ & $P$ value $^{\mathrm{b}}$ & $P$ value ${ }^{c}$ \\
\hline Patients in exacerbation & 25 & $6.93 \pm 1.18$ & 0.834 & 0.001 & 0.001 \\
\hline Patients in remission & 18 & $6.56 \pm 1.32$ & & 0.002 & 0.002 \\
\hline Ocular MG & 11 & $16.08 \pm 2.88$ & & & 0.978 \\
\hline Healthy controls & 10 & $15.97 \pm 2.88$ & & & \\
\hline
\end{tabular}

CD1 ${ }^{+}$CD5 ${ }^{+}$CD19 represent the Breg cells; the results represent the mean \pm standard error; $P$ value ${ }^{a}$ as compared between the patients in exacerbation and patients in remission; $P$ value $^{\mathrm{b}}$ as compared with ocular MG; $P$ value ${ }^{\mathrm{c}}$ as compared with healthy controls. MG: myasthenia gravis

Table 4: Frequencies of NK cells in the peripheral blood of MG patients (\%)

\begin{tabular}{|c|c|c|c|c|c|}
\hline Group & Number & $\mathrm{CD}^{-} \mathrm{CD}^{-19}{ }^{+} \mathrm{CD} 6^{+} \mathrm{NK}$ cells & $P$ value $^{a}$ & $P$ value $^{\mathrm{b}}$ & $P$ value $^{c}$ \\
\hline Patients in exacerbation & 25 & $12.32 \pm 1.42$ & 0.017 & 0.126 & 0.569 \\
\hline Patients in remission & 18 & $20.69 \pm 3.45$ & & 0.751 & 0.017 \\
\hline Ocular MG & 11 & $18.98 \pm 3.81$ & & & 0.077 \\
\hline Healthy controls & 10 & $11.33 \pm 0.95$ & & & \\
\hline
\end{tabular}

$\mathrm{CD}^{\circ} \mathrm{CD} 19^{+} \mathrm{CD}^{+} 6^{+}$cells represent the NK cells. The results represent the mean \pm standard error; $P$ value as compared between the patients in exacerbation and ones in remission; $P$ value ${ }^{b}$ as compared with ocular MG patients; $P$ value ${ }^{c}$ as compared with the healthy controls. NK: natural killer; MG: myasthenia gravis 
will lead to of muscle weakness in MG patients. Among the predisposing factors, infections were the most frequently identified for symptomatic exacerbation in our study [Table 5]. So, we have further analyzed peripheral blood lymphocyte subsets in the patients with infections at the exacerbation stage. Our data showed that the patients with infections had significantly lower percentage of NK cells those without infections during exacerbation (10.97 \pm 1.74 ;
$14.03 \pm 2.36$, Table 5, Figure 3 ), suggesting that the NK cells may be consumed by infections or by a similar mechanism during deterioration of muscle weakness. Furthermore, the difference in NK cells percentages between the patients in exacerbation with infections and the cases in remission was significant $(P=0.028)$, but the difference between the patients in exacerbation without infections and the cases in remission was not statistically significant [Table 5; Figure 3]. The

Table 5: Frequencies of NK and Breg cells in PE with infection and without infection (\%)

\begin{tabular}{|c|c|c|c|c|c|c|c|c|}
\hline \multirow{2}{*}{ Group } & \multicolumn{4}{|c|}{ Breg cells } & \multicolumn{4}{|c|}{ NK cells } \\
\hline & Frequencies & $P$ value $^{a}$ & $P$ value $^{c}$ & $P$ value $^{d}$ & Frequencies & $P$ value ${ }^{a}$ & $P$ value $^{c}$ & $P$ value ${ }^{d}$ \\
\hline PE with infection (14) & $6.84 \pm 1.59$ & 0.891 & 0.007 & 0.931 & $10.97 \pm 1.74$ & 0.028 & 0.871 & 0.295 \\
\hline PE without infection (11) & $7.05 \pm 1.85$ & 0.825 & 0.016 & & $14.03 \pm 2.36$ & 0.177 & 0.307 & \\
\hline Patients in remission (18) & $6.56 \pm 1.32$ & & 0.002 & & $20.69 \pm 3.45$ & & 0.017 & \\
\hline Healthy controls (10) & $15.97 \pm 2.88$ & & & & $11.33 \pm 0.95$ & & & \\
\hline
\end{tabular}

The results represent the mean \pm standard error; $P$ value ${ }^{a}$ as compared between the patients in exacerbation and the ones in remission; $P$ value $^{c}$ as compared with the healthy controls. $P$ value ${ }^{d}$ as compared between PE patients with infection and without infection. NK: natural killer; PE: patients in exacerbation

A

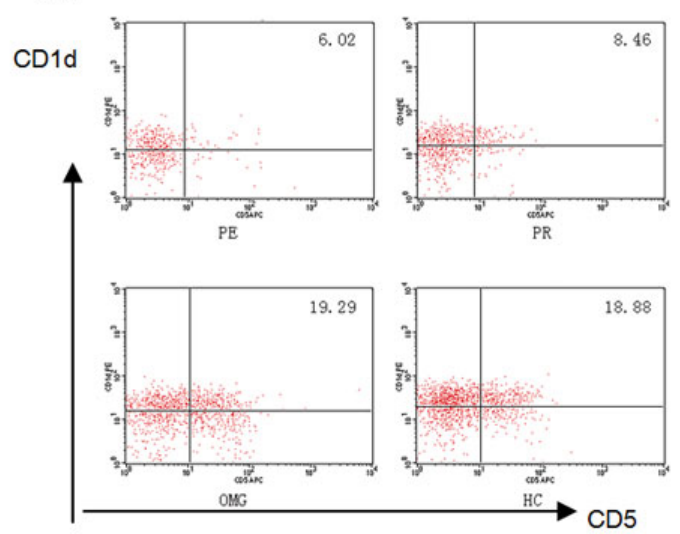

B

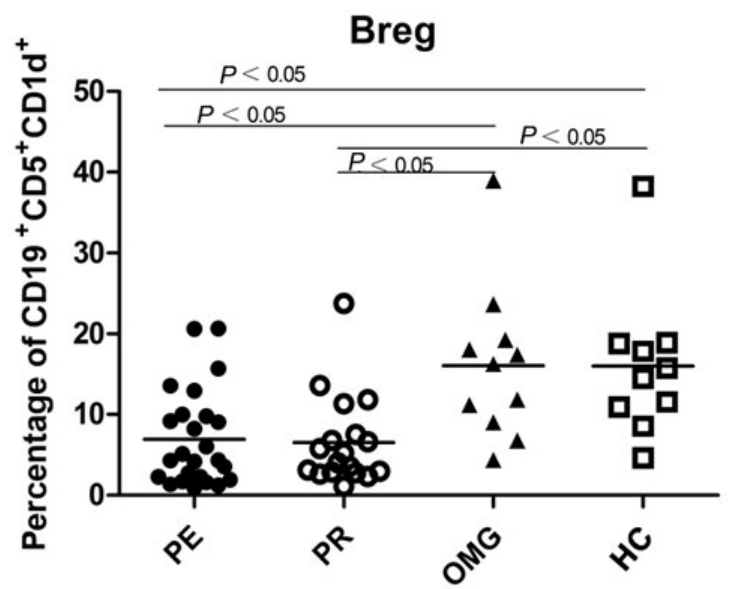

Figure 1: (A) Breg cells flow cytometry scatter plot in the PE, PR, OMG patients and the HC; (B) the percentage of Breg cells in GMG significantly lower than those in the OMG patients and in the controls, the difference was statistically significant $(P<0.05)$, but there was no obvious difference between the two subgroups of GMG patients. PE: patients in exacerbation; PR: patients in remission; OMG: ocular myasthenia gravis; HC: healthy controls; GMG: generalized myasthenia gravis

A

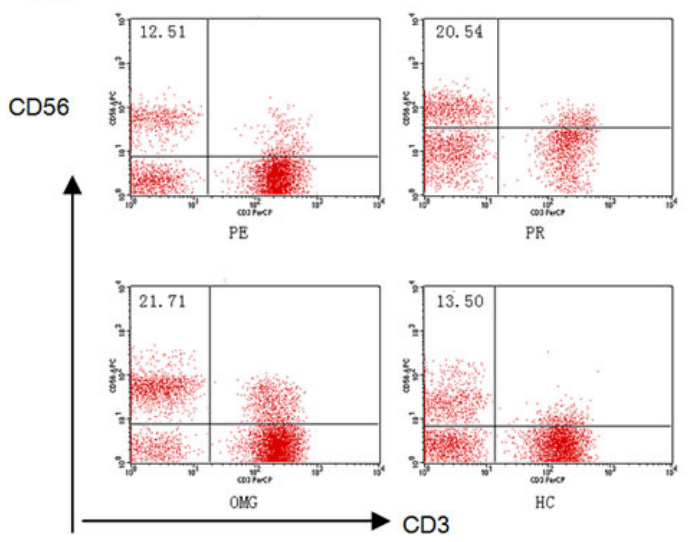

B

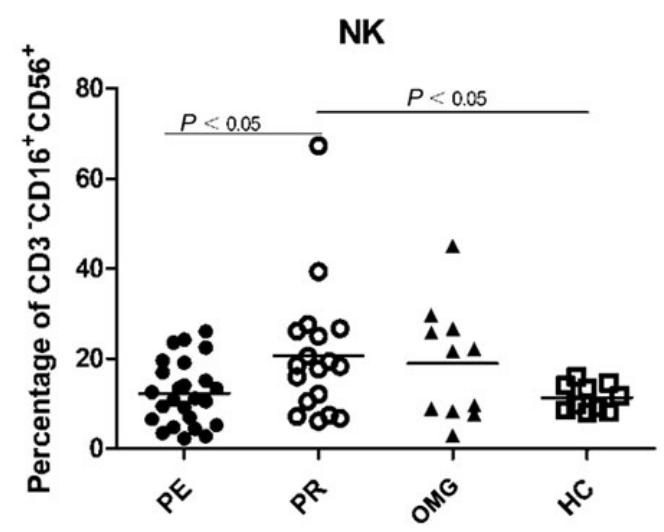

Figure 2: (A) NK cells flow cytometry scatter plot in the PE, PR, OMG patients and the HC; (B) the percentage of NK cells in the patients remission significantly higher than that in the patients in exacerbation and the healthy controls $(P<0.05)$. NK: natural killer; PE: patients in exacerbation; PR: patients in remission; OMG: ocular myasthenia gravis; HC: healthy controls 
percentage of Bregs did not differ between the patients in exacerbation with infections $(6.84 \pm 1.59)$ and those without infections $(7.05 \pm 1.85)$.

\section{DISCUSSION}

Disorders of neuromuscular junction can be of immunological, toxic, or genetic origin; and among these rare disorders, MG is the most common. The clinical hallmark of MG is a fluctuating weakness and fatigability of the affected voluntary muscles. With the advent of immunotherapy, the long-term outcome has been improved significantly, ${ }^{[39]}$ but the symptomatic deterioration after symptomatic remission takes places in majority of MG patients including both the OMG and GMG cases. ${ }^{[40-42]}$ Thus, reliable markers that reflect the activity of the disease to guide the clinical therapy are critical.

MG patients present with heterogeneous clinical patterns in terms of onset-age, initial symptoms, mode of development, thymic abnormalities, immunological profiles, and responsiveness to treatment. MG is currently considered to consist of a heterogeneous group of autoimmune diseases, which share common aspects, such as the impairment of neuromuscular transmission induced by autoimmunity, manifested by muscle weakness and fatigability and the response to both pyridostigmine and immunosuppressants. ${ }^{[43]}$

In MG, the presence of multiple autoantibodies against numerous targeted molecules (e.g. AChR-ab). These

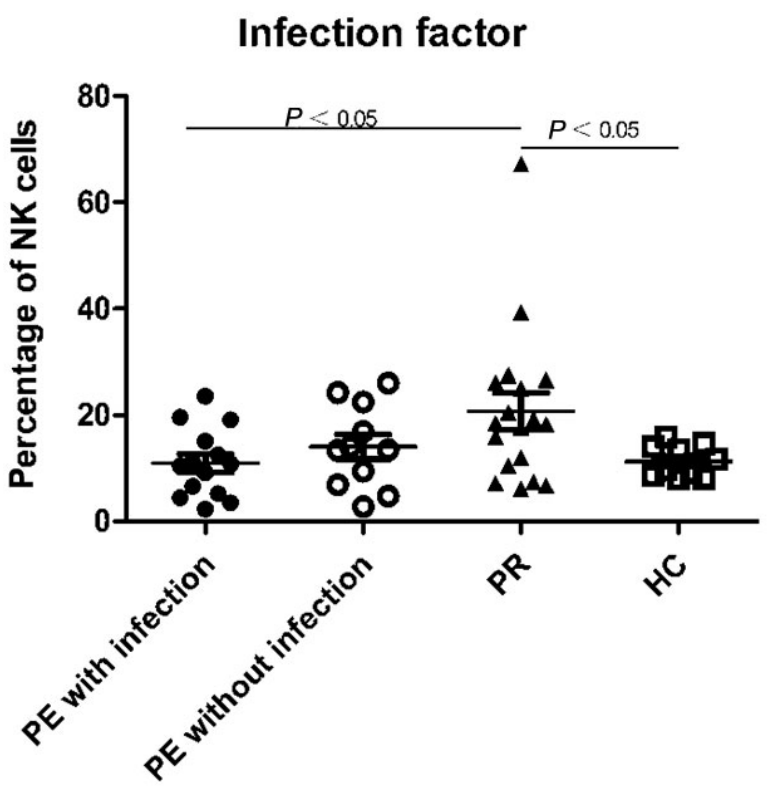

Figure 3: The percentage of NK cells in PE with infections was statistically lower than PR. The difference between PR and PE without infections was not statistically significant. NK: natural killer; PE: patients in exacerbation; PR: patients in remission; HC: healthy controls antibodies suggest altered immunity, but any single antibody determination is hardly reflective of the progression or activity of the disease. The production of the above-mentioned antibodies are likely the result of the dysfunctioned lymphocytes, thus measuring the peripheral lymphocytes subsets in MG patients may be a promising way to monitor the progression of the disease.

B cell abnormalities contribute to the development and progress of autoimmune diseases. Traditionally, the predominant function of $B$ cells was thought to be limited to production of autoantibodies. However, $B$ cells have both positive and negative regulatory roles during immune responses. During murine development the absence of $B$ cells results in significant quantitative and qualitative abnormalities within the immune system, including a remarkable decrease in thymocytes numbers, ${ }^{[44]}$ defects within spleen dendritic cells and T cells compartments. ${ }^{[45,46]}$ Through production of immunomodulatory cytokines, $B$ cells can also negatively regulate cellular immune responses. A variety of regulatory $B$ cell subsets have been described. Whether Breg cells can serve as a marker for disease activity in MG remains to be determined. Our observation showed that the percentage of Breg cells was significantly decreased in the peripheral blood of GMG patients, indicating that Breg cells are affected during the development of the disease. But when we further focused on the changes of Breg cells between the two subgroups of GMG, no significant difference was found between them. This interesting finding suggests that the peripheral Breg cells dysfunction may contribute to the development of MG, but are likely not a main factor in the acute exacerbation of disease. Thus, more detailed studies on the subsets of Breg cells may provide valuable insights into the role of Breg cells in MG.

NK cells are large granular cells that constitute $5-10 \%$ of circulating lymphocytes in humans, and are important effectors in innate immunity. ${ }^{[29]}$ Increasing studies report that NK cells can also act as regulators in adaptive immunity by producing cytokines which modulate the downstream immune factors. ${ }^{[47-49]}$ In addition, NK cells were found to play a protective role in several autoimmune disease models. ${ }^{[50-52]}$ In EAMG, Liu et al. ${ }^{[53]}$ reported that NK cells proliferate in the early stages of the disease; the percentage of NK cells then decrease with disease progression. Based on the observations, NK cells were suggested to activate $\mathrm{CD}^{+} \mathrm{T}$ lymphocytes. A previous report showed that the activity of NK cells in the blood of MG patients was lower than that of the controls. ${ }^{[54]}$ Further, Suzuki et al. ${ }^{[55]}$ showed that the frequencies of NK cell 
subclasses were similar among the control thymuses, hyperplasic thymuses and thymomas; suggesting that circulating NK cells may have migrated to sites of inflammation. In our study, we discovered that the percentage of NK cells was increased significantly in the patients in remission stage, but nearly unchanged in exacerbation stage and in PE with infections. The data suggest that NK cells may protect against autoimmune response, especially in patients with infections; yet, the mechanism for the increase in NK cells is unknown. These findings are consistent with Suzuki et al., ${ }^{[55]}$ which suggested that NK cells in the blood of patients at exacerbation stage may transfer to the neuromuscular junction, where immune cells obviously accumulate. At the stage of remission, NK cells might then transfer back to peripheral blood. It will be very interesting to compare the NK cell density in the neuromuscular junction among the patients in different stages. However, how the NK cells migrate at different stages and how NK cells are involved in the pathogenesis of MG remains to be fully elucidated. Based on our initial study, we also suggest that developing approaches that restore and boost the activity of NK cells may improve the MG symptoms and have therapeutic value.

Studies on the immune mechanism of OMG are scarce. However, in our study, both the Breg cells and NK cells were not obviously changed in the OMG patients. Actually, childhood onset MG (CMG), predominantly manifested isolated ocular symptoms, shows many different aspects from the adult onset MG, such as the rare transformation from the ocular type to generalized types, the scarcity of thymomas, and the lacking benefit of thymectomy in CMG. ${ }^{[41]}$ We are convinced that the CMG with ocular type represents a different clinical entity in which the immunologic pathogenesis is far from being understood.

In conclusion, lymphocyte subsets were obviously disordered in GMG patients. The decrease of the peripheral Breg cells is linked with development of GMG, while the increase of peripheral NK cells is associated with reduced MG symptoms. Our research reveals that the frequency of the NK cells could be a reliable marker for MG activity in GMG patients. Restoring and boosting the activity of NK cells could be of therapeutic value. Therefore, a prospective, randomized clinical trial is required to further delineate the significance of NK cells in MG patients.

\section{DECLARATIONS}

\section{Authors' contributions}

Concept, design, and manuscript review: B.T. Bu
Concept, statistical analysis, and manuscript editing: L.X. Li

Literature search, experimental studies, manuscript preparation, and manuscript editing: X.Y. Lai

Clinical studies, and data acquisition: M.C. Gui, J. Lin, Y. Li, X. Luo, X.Y. Lai

\section{Financial support and sponsorship}

This study was supported by a grant from Natural Science Foundation of China to Dr. Bu (No. 81271320); the Outstanding Leaders Training Program of Pudong Health Bureau of Shanghai (No. PWR12014-05); the Key Specialty Construction Project of Shanghai Municipal Health Bureau (No. ZK2015B16); the 100-Talents Program of the Shanghai Municipal Health Bureau (No. 2017BR051).

\section{Conflicts of interest}

There are no conflicts of interest.

\section{Patient consent}

All the participants signed the informed consent prior to the enrollment.

\section{Ethics approval}

The study has been approved by the Ethics Committee of Huazhong University of Science and Technology.

\section{REFERENCES}

1. Meriggioli MN, Sanders DB. Autoimmune myasthenia gravis: emerging clinical and biological heterogeneity. Lancet Neuro 2009;8:475-90.

2. Mantegazza R, Bonanno S, Camera G, Antozzi C. Current and emerging therapies for the treatment of myasthenia gravis. Neuropsychiatr Dis Treat 2011;7:151-60.

3. Strober J, Cowan MJ, Horn BN. Allogeneic hematopoietic cell transplantation for refractory myasthenia gravis. Arch Neurol 2009;66:659-61.

4. Tuzun E, Huda R, Christadoss P. Complement and cytokine based therapeutic strategies in myasthenia gravis. $J$ Autoimmun 2011;37:136-43.

5. Zhou Y, Gong B, Lin F, Rother RP, Medof ME, Kaminski HJ. Anti-C5 antibody treatment ameliorates weakness in experimentally acquired myasthenia gravis. J Immunol 2007; 179:8562-7.

6. Masuda T, Motomura M, Utsugisawa K, Nagane Y, Nakata R, Tokuda M, Fukuda T, Yoshimura T, Tsujihata M, Kawakami A. Antibodies against the main immunogenic region of the acetylcholine receptor correlate with disease severity in myasthenia gravis. J Neuro Neurosurg Psychiatry 2012;83:935-40.

7. Liu A, Lin H, Liu Y, Cao X, Wang X, Li Z. Correlation of C3 level with severity of generalized myasthenia gravis. Muscle Nerve 2009;40:801-8.

8. Zhang B, Tzartos JS, Belimezi M, Ragheb S, Bealmear B, Lewis RA, Xiong WC, Lisak RP, Tzartos SJ, Mei L. Autoantibodies to lipoprotein-related protein 4 in patients with double-seronegative myasthenia gravis. Arch Neurol 2012;69:445-51.

9. Suzuki S, Utsugisawa K, Nagane Y, Suzuki N. Three types of striational antibodies in myasthenia gravis. Autoimmun Dis 2011;2011:740583. 
10. Romi F, Aarli JA, Gilhus NE. Myasthenia gravis patients with ryanodine receptor antibodies have distinctive clinical features. Euro J Neurol 2007;14:617-20.

11. Richman DP, Nishi K, Morell SW, Chang JM, Ferns MJ, Wollmann RL, Maselli RA, Schnier J, Agius MA. Acute severe animal model of anti-muscle-specific kinase myasthenia: combined postsynaptic and presynaptic changes. Arch Neurol 2012;69:453-60.

12. Li WX, Pan HF, Hu JL, Wang CZ, Zhang N, Li J, Li XP, Xu JH, Ye DQ. Assay of T- and NK-cell subsets and the expression of NKG2A and NKG2D in patients with new-onset systemic lupus erythematosus. Clin Rheumatol 2010;29:315-23.

13. Caldwell CW, Bridges AJ, Walker SE, Smarr KL, Reichert RJ, Anderson SK, Hewett JE, Parker JC. A controlled study of lymphocyte subsets in rheumatoid arthritis. Clin Immunol Immunopathol 1992;63:237-44.

14. Goto Y, Itoh M, Ogawa N, Goto Y, Ohashi H, Ohno R. Increased production of B cell growth factor (BCGF) in Sjogren's syndrome. $J$ Autoimmun 1996;9:545-50.

15. Szodoray P, Gal I, Barath S, Aleksza M, Horvath IF, Gergely P Jr, Szegedi G, Nakken B, Zeher M. Immunological alterations in newly diagnosed primary Sjogren's syndrome characterized by skewed peripheral T-cell subsets and inflammatory cytokines. Scand J Rheumatol 2008;37:205-12.

16. Chien PJ, Yeh JH, Shih CM, Hsueh YM, Chen MC, Chiu HC. A decrease in the percentage of $\mathrm{CD} 3+$ cells is correlated with clinical improvement during plasmapheresis in patients with myasthenia gravis. Artif Organs 2013;37:211-6.

17. Li X, Xiao BG, Xi JY, Lu CZ, Lu JH. Decrease of CD4(+)CD25(high) Foxp3(+) regulatory $\mathrm{T}$ cells and elevation of CD19(+)BAFF-R $(+)$ $\mathrm{B}$ cells and soluble ICAM-1 in myasthenia gravis. Clin Immunol 2008;126:180-8.

18. Suzuki Y, Onodera H, Tago H, Saito R, Ohuchi M, Shimizu M, Matsumura Y, Kondo T, Yoshie O, Itoyama Y. Altered expression of Th1-type chemokine receptor CXCR3 on CD4+ T cells in myasthenia gravis patients. J Neuroimmunol 2006;172:166-74.

19. Teleshova N, Matusevicius D, Kivisakk P, Mustafa M, Pirskanen R, Link H. Altered expression of costimulatory molecules in myasthenia gravis. Muscle Nerve 2000;23:946-53.

20. Conti-Fine BM, Milani M, Wang W. CD4+ T cells and cytokines in the pathogenesis of acquired myasthenia gravis. Ann $N$ Y Acad Sci 2008;1132:193-209.

21. Masuda M, Matsumoto M, Tanaka S, Nakajima K, Yamada N, Ido N, Ohtsuka T, Nishida M, Hirano T, Utsumi H. Clinical implication of peripheral CD4+CD25+ regulatory $\mathrm{T}$ cells and Th17 cells in myasthenia gravis patients. J Neuroimmunol 2010;225:123-31.

22. Han J, Sun L, Fan X, Wang Z, Cheng Y, Zhu J, Jin T. Role of regulatory b cells in neuroimmunologic disorders. $J$ Neurosci Res 2016;94:693-701.

23. Loza MJ, Zamai L, Azzoni L, Rosati E, Perussia B. Expression of type 1 (interferon gamma) and type 2 (interleukin-13, interleukin-5) cytokines at distinct stages of natural killer cell differentiation from progenitor cells. Blood 2002;99:1273-81.

24. French AR, Yokoyama WM. Natural killer cells and autoimmunity. Arthritis Res Ther 2004;6:8-14.

25. Shi FD, Ljunggren HG, Sarvetnick N. Innate immunity and autoimmunity: from self-protection to self-destruction. Trends Immunol 2001;22:97-101.

26. Zimmer J, Bausinger H, de la Salle H. Autoimmunity mediated by innate immune effector cells. Trends Immunol 2001;22:300-1.

27. Grom AA. Natural killer cell dysfunction: a common pathway in systemic-onset juvenile rheumatoid arthritis, macrophage activation syndrome, and hemophagocytic lymphohistiocytosis? Arthritis Rheum 2004;50:689-98.
28. Shibatomi K, Ida H, Yamasaki S, Nakashima T, Origuchi T, Kawakami A, Migita K, Kawabe Y, Tsujihata M, Anderson P, Eguchi K. A novel role for interleukin-18 in human natural killer cell death: high serum levels and low natural killer cell numbers in patients with systemic autoimmune diseases. Arthritis Rheum 2001;44:884-92.

29. Trinchieri G. Biology of natural killer cells. Adv Immunol 1989;47:187-376.

30. DiLillo DJ, Matsushita T, Tedder TF. B10 cells and regulatory B cells balance immune responses during inflammation, autoimmunity, and cancer. Ann N Y Acad Sci 2010;1183:38-57.

31. Kalampokis I, Yoshizaki A, Tedder TF. IL-10-producing regulatory B cells (B10 cells) in autoimmune disease. Arthritis Res Ther 2013;15 Suppl 1:S1.

32. Mizoguchi A, Bhan AK. A case for regulatory B cells. J Immunol 2006; 176:705-10.

33. Sheng JR, Quan S, Soliven B. CD1d(hi)CD5+ B cells expanded by GM-CSF in vivo suppress experimental autoimmune myasthenia gravis. J Immunol 2014;193:2669-77.

34. Blair PA, Noreña LY, Flores-Borja F, Rawlings DJ, Isenberg DA, Ehrenstein MR, Mauri C. CD19(+)CD24(hi)CD38(hi) B cells exhibit regulatory capacity in healthy individuals but are functionally impaired in systemic Lupus Erythematosus patients. Immunity 2010;32:129-40.

35. Sun F, Ladha SS, Yang L, Liu Q, Shi SX, Su N, Bomprezzi R, Shi FD. Interleukin-10 producing-B cells and their association with responsiveness to rituximab in myasthenia gravis. Muscle Nerve 2014;49:487-94.

36. Zha B, Wang L, Liu X, Liu J, Chen Z, Xu J, Sheng L, Li Y, Chu Y. Decrease in proportion of CD19+ CD24(hi) CD27+ B cells and impairment of their suppressive function in Graves' disease. PLoS One 2012; 7:e49835.

37. Jaretzki A 3rd, Barohn RJ, Ernstoff RM, Kaminski HJ, Keesey JC, Penn AS, Sanders DB. Myasthenia gravis: recommendations for clinical research standards. Task Force of the Medical Scientific Advisory Board of the Myasthenia Gravis Foundation of America. Ann Thorac Surg 2000;70:327-34.

38. Yanaba K, Bouaziz JD, Haas KM, Poe JC, Fujimoto M, Tedder TF. A regulatory $\mathrm{B}$ cell subset with a unique $\mathrm{CD} 1 \mathrm{dhiCD5}+$ phenotype controls $\mathrm{T}$ cell-dependent inflammatory responses. Immunity 2008;28:639-50.

39. Liu C, Wang Q, Qiu Z, Lin J, Chen B, Li Y, Gui M, Zhang M, Yang M, Wang W, Bu B. Analysis of mortality and related factors in 2195 adult myasthenia gravis patients in a 10-year follow-up study. Neurol India 2017;65:518-24.

40. Yu S, Li F, Chen B, Lin J, Yang M, Fu X, Li J, Bu B. Eight-year follow-up of patients with myasthenia gravis after thymectomy. Acta Neurol Scand 2015;131:94-101.

41. Gui M, Luo X, Lin J, Li Y, Zhang M, Zhang X, Yang M, Wang W, $\mathrm{Bu}$ B. Long-term outcome of 424 childhood-onset myasthenia gravis patients. J Neurol 2015;262:823-30.

42. Yu S, Lin J, Fu X, Li J, Li Y, Chen B, Yang M, Zhang M, Bu B. Risk factors of myasthenic crisis after thymectomy in 178 generalized myasthenia gravis patients in a five-year follow-up study. Int $J$ Nneurosci 2014;124:792-8.

43. Sieb JP. Myasthenia gravis: an update for the clinician. Clin Exp Immunol 2014;175:408-18.

44. Joao C, Ogle BM, Gay-Rabinstein C, Platt JL, Cascalho M. B celldependent TCR diversification. J Immunol 2004;172:4709-16.

45. Ngo VN, Cornall RJ, Cyster JG. Splenic T zone development is B cell dependent. J Exp Med 2001;194:1649-60.

46. Moulin V, Andris F, Thielemans K, Maliszewski C, Urbain J, Moser M. B lymphocytes regulate dendritic cell (DC) function in vivo: increased interleukin 12 production by DCs from B cell-deficient mice 
results in T helper cell type 1 deviation. $J$ Exp Med 2000;192:475-82.

47. Raulet DH. Interplay of natural killer cells and their receptors with the adaptive immune response. Nat Immunol 2004;5:996-1002.

48. Vivier E, Malissen B. Innate and adaptive immunity: specificities and signaling hierarchies revisited. Nat Immunol 2005;6:17-21.

49. Walzer T, Dalod M, Robbins SH, Zitvogel L, Vivier E. Naturalkiller cells and dendritic cells: "l'union fait la force". Blood 2005; 106:2252-8

50. Fairweather D, Kaya Z, Shellam GR, Lawson CM, Rose NR. From infection to autoimmunity. J Autoimmun 2001;16:175-86.

51. Maity R, Nair SR, Caspi RR, Nelson LM. Post-thymectomy murine experimental autoimmune oophoritis is associated with reduced natural killer cell activity. Am J Reprod Immunol 1997;38:360-5.

52. Shi FD, Zhou Q. Natural killer cells as indispensable players and therapeutic targets in autoimmunity. Autoimmunity 2011;44:3-10.

53. Liu R, Van Kaer L, La Cava A, Price M, Campagnolo DI, Collins M, Young DA, Vollmer TL, Shi FD. Autoreactive T cells mediate NK cell degeneration in autoimmune disease. J Immunol 2006;176:5247-54.

54. Kott E, Hahn T, Huberman M, Levin S, Schattner A. Interferon system and natural killer cell activity in myasthenia gravis. $Q \mathrm{~J}$ Med 1990;76:951-60

55. Suzuki Y, Onodera H, Tago H, Saito R, Ohuchi M, Shimizu M, Itoyama Y. Altered populations of natural killer cell and natural killer T cell subclasses in myasthenia gravis. J Neuroimmunol 2005;167:186-9. 